\title{
Requirement of dual stimulation by homologous recombinant IL-2 and recombinant IL-12 for the in vitro production of interferon gamma by canine peripheral blood mononuclear cells
}

\author{
Andrea Mendes Pereira', Cristiane Garboggini Melo de Pinheiro ${ }^{1}$, Lenita Ramires dos Santos ${ }^{1}$, \\ Naiara Carvalho Teixeira', Yung-Fu Chang ${ }^{2}$, Lain Carlos Pontes-de-Carvalho ${ }^{1}$ and Geraldo Gileno de Sá Oliveira ${ }^{1,3^{*}}$
}

\begin{abstract}
Background: Very few studies have been carried out so far aiming at modulating cellular immune responses in dogs. In this study, we evaluated the ability of recombinant canine IL-2 (rcalL-2) and IL-12, in the form of a single-chain fusion protein (rsccall-12), to stimulate peripheral blood mononuclear cells (PBMC) of healthy mongrel dogs.

Results: Recombinant canine IL-2 purified from Escherichia coli or present in the supernatant of COS-7 cells transfected with pcDNA3.1-calL-2 (COS-7 calL-2 supernatant) was able to induce proliferation of CTLL-2 cells, thus showing their functional activity. In addition, purified rcall-2 and COS-7 call-2 supernatant stimulated resting canine PBMC proliferation to a level higher than baseline level. Neither COS-7 sccalL-12 supernatant nor COS-7 call-2 supernatant alone was able to induce significant production of interferon gamma by resting PBMC. However, COS-7 sccalL-12 supernatant in combination with COS-7 call-2 supernatant induced production of IFN- $\gamma$ by those cells.

Conclusions: The data shown herein suggest that the combination of canine recombinant IL-12 and IL-2 can be useful to promote cellular immune responses in dogs.
\end{abstract}

Keywords: Interleukin 2, Interleukin 12, Cellular immune response, Dog

\section{Background}

Cytokines are proteins or glycoproteins produced mainly by cells of the immune system. They participate in several different biological processes, including the homeostasis of the immune system and the generation of immune responses [1,2]. To exert their biological activities, cytokines bind to specific receptors on the cytoplasmic membrane of the target cells and activate intracellular signaling pathways that result in the generation of transcription factors and expression of several genes [3]. Being involved in the initiation, effector mechanisms and regulation of inflammation, as well as in the

\footnotetext{
* Correspondence: ggileno@bahia.fiocruz.br

'Laboratório de Patologia e Bio-Intervenção, Centro de Pesquisas Gonçalo Moniz, Fundação Oswaldo Cruz, Rua Waldemar Falcão, No. 121, Candeal, Salvador, Bahia, Brazil

${ }^{3}$ Instituto Nacional de Ciência e Tecnologia de Doenças Tropicais (INCT-DT), Salvador, Bahia, Brazil

Full list of author information is available at the end of the article
}

immune responses, cytokines contribute both to the development and control of many different diseases, including the infectious, parasitic, allergic, autoimmune and neoplastic diseases. Therefore, substances that interfere with cytokine signaling pathways, both agonists and antagonists, may be useful for the prophylaxis or therapy of a great number of diseases.

There is a large amount of data showing that the manipulation of the immune system by interference in cytokine signaling changes the outcome of various diseases in the murine model. However, no studies comparable to those carried out in mice that could encourage the development of new therapeutic approaches for canine diseases have been reported in the dog.

The control of infection by intracellular pathogens can be initiated by stimulation of natural killer (NK) cells and be established by cellular immune responses involving $\mathrm{CD} 4^{+} \mathrm{T}$ cells, activation of macrophages, and $\mathrm{CD} 8^{+} \mathrm{T}$ cells 
[4]. Little is known, however, about conditions that promote cellular immune responses in dogs.

Interleukin-2 (IL-2) was the first cytokine to be tested in a purified state or cloned [5,6]. IL-2 is produced mainly by $\mathrm{CD}^{+} \mathrm{T}$ cells and $\mathrm{CD}^{+} \mathrm{T}$ cells activated by antigen $[7,8]$. It performs various activities in the immune system, including promotion of differentiation of $\mathrm{CD}^{+}{ }^{+} \mathrm{T}$ helper-1 (Th1) and -2 (Th2) cells, maintenance of $\mathrm{CD}^{+}$regulatory $\mathrm{T}$ (Treg) cells and optimization of the expansion of $\mathrm{CD}^{+}$effector $\mathrm{T}$ cells and $\mathrm{CD}^{+}$memory T cells [9].

IL-12 is a heterodimeric cytokine produced by antigenpresenting cells (dendritic cells, macrophages and B cells) that, alone or synergistically with other factors, e.g., IL-2 or mitogens, displays the ability to stimulate the production of interferon gamma (IFN- $\gamma$ ) in resting or activated NK and T cells [10]. IL-12 is also able to promote the cytotoxic activity and proliferation of NK and T cells [10]. Furthermore, IL-12 contributes to the generation of Th1 lymphocytes [11], which are required for controlling infections by intracellular pathogens.

Although several authors have reported some consequences of the exposure of recombinant human IL-2 (rhuIL-2) or IL-12 (rhuIL-12) on canine systems in vitro and in vivo [12-18], reports on the exposure of canine cells to recombinant canine IL-2 (rcalL-2) do not exist and to recombinant canine IL-12 (rcalL-12) still provide insufficient knowledge to allow for the exploitation of the full potential of this cytokine in the manipulation the immune system of dogs [19-23]. The administration of heterologous cytokines in animals, even when the homology between the donor and receptor species is high, may result in the production of specific antibodies with the potential ability to prevent the action of long-lasting treatments [24-26]. Therefore, in order to manipulate the canine immune system for long-term, it would be better to use homologous instead of heterologous cytokines.

Since IL-2 synergizes with IL-12 to promote NK and T cell proliferation, cytotoxic activity, and IFN- $\gamma$ production [27-30], it would be interesting to study the effects of the combination of these two cytokines in dogs. In this paper, cloning of canine IL-2, expression of rcalL-2 and rcalL-12 and the ability of these cytokines to stimulate canine PBMC are reported.

\section{Methods}

\section{Cloning, production and purification of canine IL-2}

The cDNA of canine IL-2 was inserted into a plasmid either for expression in Escherichia coli or in mammalian cells, using conventional methods. Briefly, the cDNA encoding the mature protein was amplified by PCR from a pCRII-2-caIL-2 template (kindly donated by Dunham, Department of Veterinary Pathology, University of Glasgow Veterinary School, United Kingdom) with specific primers (forward 5' -CGCGGATCCGGCACCTATTACT TCAAG and reverse $5^{\prime}$-CCGGAATTCTCAAGTCAGT GTTGAG) and digested. The digestion product was inserted into pRSET (Invitrogen Corporation, Carlsbad, EUA) using the BamHI/EcoRI site, generating the pRSETcalL-2 construction.

The cDNA encoding the whole IL-2 protein was amplified by RT-PCR from canine PBMC, after their stimulation with $10 \mu \mathrm{g} / \mathrm{mL}$ concanavalin A (Con A, SigmaAldrich, St. Louis, USA) for $24 \mathrm{~h}$ at $37^{\circ} \mathrm{C}$ in a $5 \% \mathrm{CO}_{2}$ atmosphere, using specific primers (forward $5^{\prime}$-CGCG GATCCAAGCCACCATGGGCAAAATGCAACTCTTG TCTTGC and reverse 5' -CCGGAATTCTCAAGTCAG TGTTGAGAAGATGC). The cDNA was digested and inserted into the BamHI/EcoRI site of the pcDNA3.1 plasmid (Invitrogen), resulting in the construction pcDNA3.1-caIL-2.

The plasmid DNA molecules with the inserts were sequenced in an ABI3100 automatic sequencer (Applied Biosystems, Foster City, CA, USA).

The production of rcalL-2 was performed in BL21 strain (DE3)pLysS E. coli (Invitrogen) transformed with pRSET-caIL-2 following the manufacturer's recommendations. The bacterial cell pellet, obtained by centrifugation after inducing the protein expression for $5 \mathrm{~h}$ with $1 \mathrm{mM}$ isopropyl- $\beta$-D-thiogalactoside (IPTG), was sus-

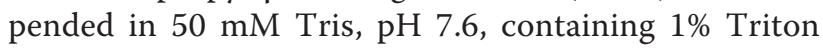
$\mathrm{X}-100(\mathrm{v} / \mathrm{v})$ and $1 \mathrm{mg} / \mathrm{mL}$ lysozyme. The suspension was then subjected to ultrasonication. The inclusion bodies were collected by centrifugation, solubilized in $20 \mathrm{mM} \mathrm{Na} \mathrm{HPO}_{4}, 500 \mathrm{mM} \mathrm{NaCl}, 10 \mathrm{mM}$ imidazole and $8 \mathrm{M}$ urea, $\mathrm{pH} 7.4$, and purified in a nickel-Sepharose affinity column (Amersham Biosciences, Uppsalla, Sweden), following the manufacturer's recommendations. The purified protein was refolded using the dialysis method described by Guisez and collaborators [31] and the protein concentration was determined by Bradford's method.

The purity of the affinity-purified IL-2 was assessed by polyacrylamide gel electrophoresis in the presence of sodium dodecyl sulfate (SDS- PAGE) and by Western blot using anti-histidine monoclonal antibody (Invitrogen). His-tagged recombinant green fluorescent protein (EGFP), produced in BL21(DE3)pLysS E. coli, and chromatographically affinity purified, was used as a positive control. To promote stability of the purified protein, bovine serum albumin was added to achieve a final concentration of $1 \mathrm{mg} / \mathrm{mL}$ [31]. Aliquots were prepared and stored at $-20^{\circ} \mathrm{C}$ until use.

\section{Expression of canine IL-2 and IL-12 in eukaryotic cells}

Recombinant canine IL-2 and IL-12 were separately expressed into culture supernatants of COS-7 cells transfected with pcDNA3.1-caIL-2 or pcDNA3.1-sccaIL-12, using the method previously described [20]. The latter 
encodes IL-12 protein in the form of a single chain fusion protein [20]. Supernant of COS-7 cells transfected for $48 \mathrm{~h}$ with pcDNA3.1-calL-2 (COS-7 calL-2 SN), pcDNA3.1sccalL-12 (COS-7 sccalL-IL-12 SN) or pcDNA3.1 without insert (COS-7 SN-negative control) were collected and stored at $-20^{\circ} \mathrm{C}$ until use.

\section{Assessment of biological activity of recombinant canine IL-2 (rcalL-2)}

The biological activity of rcalL-2 produced in E. coli or COS-7 cells was evaluated using CTLL-2 cells (TIB-214 cells, American Type Culture Collection, ATCC, USA), essentially as previously described [32]. Briefly, in triplicate wells of 96-well flat bottom microtiter plates (Corning Incorporated), $10^{4}$ CTLL-2 cells/well in RPMI 1640 culture medium supplemented with $2 \mathrm{mM}$ of sodium pyruvate, $2 \mathrm{mM}$ of L-glutamine and 10\% fetal calf serum (supplemented RPMI 1640) were cultured with: 1) rcalL-2 purified from $E$. coli at final concentrations between $9 \mathrm{pg} / \mathrm{mL}$ and $700 \mathrm{ng} / \mathrm{mL}$; 2) COS-7 caIL-2 SN or SN COS-7-negative control at final concentrations between 0.39 and $12.5 \%$; 3 ) supernant of rat splenocytes stimulated with Con A), the so-called T-STIM (BD Biosciences, Franklin Lakes, NJ, USA) at 10\% (positive control); and 4) supplemented RPMI 1640 culture medium. The plates were incubated for $24 \mathrm{~h}$ at $37^{\circ} \mathrm{C}$ in a humidified atmosphere of $5 \% \mathrm{CO}_{2}$. Thirty $\mu \mathrm{L}$ of supplemented RPMI medium containing $1 \mu \mathrm{Ci}$ of ${ }^{3} \mathrm{H}$-thymidine were then added to each well. After a further $24 \mathrm{~h}$ period of incubation, the cells were collected onto glass fiber membranes (Packard, Meriden, USA) and analyzed in a Matrix 9600 Direct Beta Counter (Packard), that generated counts per minute (CPM) values related with beta particle emission.

\section{Canine peripheral blood mononuclear cells (PBMC)}

Eight healthy adult mongrel dogs, 4 males and 4 females, were used. The animals were kept in the Gonçalo Moniz Research Center kennel with access to water and food ad libitum. All experiments were performed in accordance with the guidelines of the Oswaldo Cruz Foundation experimental animal use (Gonçalo Moniz Research Center Ethical Committee Experimental Licence Protocol 040-CPqGM). Twenty-five $\mathrm{mL}$ of blood from each dog were collected from the cephalic vein with a heparinized syringe (Heparin, Eurofarma, São Paulo, Brazil). Blood samples, diluted 1:2 in Hanks solution (HBSS, Sigma-Aldrich) buffered with $10 \mathrm{mM}$ HEPES (Invitrogen), pH 7.0, were placed onto Fycoll-Hypaque (SigmaAldrich) and centrifuged for 35 minutes at $800 \times \mathrm{g}$, at $20^{\circ} \mathrm{C}$. The mononuclear cells were collected, washed twice with buffered HBSS and suspended in RPMI 1640 supplemented with $10 \mathrm{mM}$ HEPES, $10 \mu \mathrm{M}$ 2-mercaptoethanol (complete RPMI 1640) and $50 \mu \mathrm{g} / \mathrm{mL}$ gentamicin sulfate (New Farma Ltda., Anapolis, Brazil) to $2 \times 10^{6} / \mathrm{mL}$.

\section{Peripheral blood lymphocyte proliferation after stimulation with rcalL-2 or COS-7 calL-2 SN}

One hundred $\mu \mathrm{L}$ suspensions of $2 \times 10^{5}$ PBMC of 6 dogs were added in triplicates to wells of 96-well flat-bottom microtiter plates. To each well it was also added a $100 \mu \mathrm{L}$ volume of: 1) rcalL-2 produced in $E$. coli, to reach a final concentration of $50 \mathrm{ng} / \mathrm{mL}$; 2) complete RPMI 1640; 3) COS-7 calL-2 SN or COS-7 SN-negative control, to achieve a final concentration of $0.5,5$ and $50 \%$. The plates were incubated at $37^{\circ} \mathrm{C}$ in a humidified atmosphere of $5 \% \mathrm{CO}_{2}$ for $4,6,8,10,12$ or 14 days. Eighteen hours before harvesting the cells, $30 \mu \mathrm{L}$ of RPMI 1640 with $1 \mu \mathrm{L} \mathrm{Ci}{ }^{3} \mathrm{H}$-thymidine were added to each well. The cells were collected and evaluated as described above.

\section{Detection of interferon gamma in cultures of PBMC stimulated with IL-12 and/or IL -2}

One hundred $\mu \mathrm{L}$ of a suspension of $2 \times 10^{5}$ PBMC were added to each well of 96-well flat-bottom microtiter plates. It was also added to the same wells, in triplicate, $100 \mu \mathrm{L}$ volumes of: 1) complete RPMI 1640; 2) Con A at $5 \mu \mathrm{g} / \mathrm{mL}$; 3) COS-7 calL-2 SN at 25\%; 4) COS-7 sccalL$12 \mathrm{SN}$ at $0.025,0.5$ or $10 \%$; or 5 ) COS-7 sccalL- $12 \mathrm{SN}$ at $0.025,0.5$ or $10 \%$ combined with COS-7 calL- 2 SN at $0.02,1,5$, or $25 \%$. The plates were incubated for $48 \mathrm{~h}$ at $37^{\circ} \mathrm{C}$ in a humidified atmosphere with $5 \% \mathrm{CO}_{2}$. The culture supernatants were removed and stored at $-20^{\circ} \mathrm{C}$ until use. The concentration of interferon gamma (IFN- $\gamma$ ) was measured in the supernatant by capture ELISA, using reagents from R\&D Systems (Minneapolis, USA) and following the manufacturer's recommendations. Briefly, 96-well high-binding microtiter plates (Corning Incorporated Life Sciences) were coated with $100 \mu \mathrm{L} /$ well of anticanine IFN- $\gamma$ at $2 \mu \mathrm{g} / \mathrm{mL}$ and blocked with $300 \mu \mathrm{L} /$ well of $1 \%$ bovine serum albumin (BSA), 5\% sucrose, and 0.05\% $\mathrm{NaN}_{3}$ in PBS. One hundred $\mu \mathrm{L}$ of the test samples were applied in duplicates to the wells. For the elaboration of a calibration curve, recombinant canine IFN- $\gamma$ was used in duplicate at concentrations between $62.5 \mathrm{pg} / \mathrm{mL}$ to $16 \mathrm{ng} /$ $\mathrm{mL}$. The following reagents were successively applied: a) anti-canine IFN- $\gamma$ - biotin conjugate at $100 \mathrm{ng} / \mathrm{mL}$; 2) streptavidin-peroxidase conjugate diluted 1:200; and 3) tetramethylbenzidine substrate (Sigma- Aldrich). The reaction was stopped by adding $50 \mu \mathrm{L} /$ well of $1 \mathrm{M} \mathrm{H}_{2} \mathrm{SO}_{4}$ and the plates were analyzed at $450 \mathrm{~nm}$ in an Emax Precison Microplate Reader (Molecular Devices Corporation, Sunnyvale, USA). The concentration of canine IFN- $\gamma$ present in each sample was estimated using the Softmax 3.0 program, corrected for the dilution factor when needed. 


\section{Statistical analysis}

For the lymphoproliferation assays, the medians of CPM were compared using the non-parametric Friedman test followed by the Dunn's test, since CPM data corresponding to thymidine incorporation generally does not have a normal distribution. The values for IFN- $\gamma$ concentration were compared by ANOVA and Dunnett's post-test. Values of $\mathrm{p}<0.05$ were considered significant.

\section{Results}

\section{Cloning of canine IL-2 and production in E. coli}

The DNA sequencing of pRSET-calL-2 construction insert showed two nucleotide mutations at positions 187 $(\mathrm{T}=>\mathrm{C})$ and $243(\mathrm{~A}=>\mathrm{G})$, in comparison with the cDNA encoding the full-length protein previously described by Dunham and collaborators [33], resulting in a substitution of a phenylalanine for a leucine $(F=>L)$ residue. This corresponds to a change of the 43rd amino acid residue in the mature protein, and the resulting recombinant protein was called rIL-2-F43L.

The DNA sequencing of pcDNA3.1-calL-2 construction insert revealed a complete identity with cDNA encoding the full-length canine IL-2, described by Dunham and collaborators [33], with the exception of the nucleotide at position $4(\mathrm{~T}=>\mathrm{G})$, deliberately changed to introduce the consensus eukaryotic ribosome binding site sequence [34].

Canine rIL-2-F43L with an N-terminus histidine tag, produced in E. coli and purified by affinity chromatography, displayed a single band with a molecular weight of $19.3 \mathrm{kDa}$ in SDS-PAGE and Western blot analysis (Figure 1).

\section{Biological activity of cloned canine IL-2}

To assess whether the canine rcalL-2-F43L subjected to refolding or the COS-7 calL-2 SN would present biological activity, the CTLL-2 cell proliferation assay was performed, and median (M) values of CPM, that are related to thymidine incorporation, were used to analyze the results. CTLL-2 cells cultured in supplemented RPMI 1640 medium alone (negative control) or stimulated with $10 \%$ T-STIM (positive control) showed no $(\mathrm{M}=14.0)$ or high $(M=73,166)$ proliferation activity, respectively. CTLL-2 cells cultured with rcalL-2-F43L in concentrations ranging from $0.22 \mathrm{ng} / \mathrm{mL}(\mathrm{M}=413)$ to $700 \mathrm{ng} / \mathrm{mL}(\mathrm{M}=$ $3,239)$ displayed higher proliferative response than cells
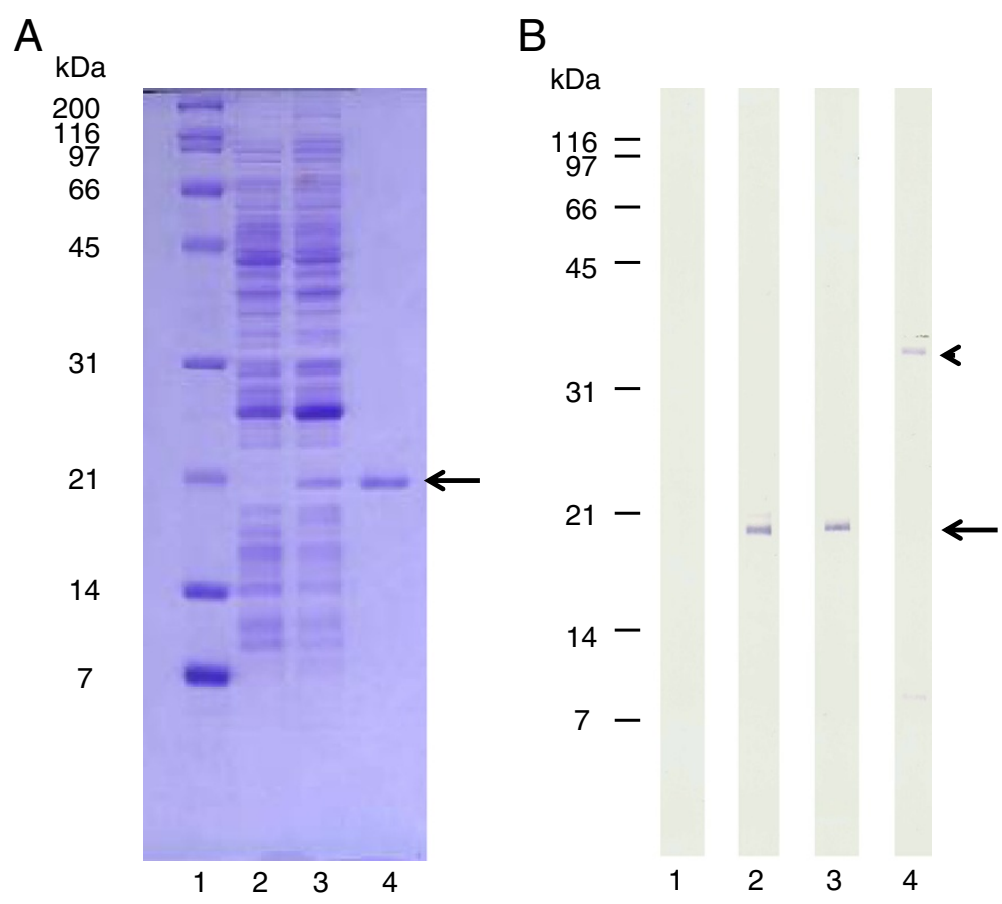

Figure 1 Evaluation of rcalL-2 expression and affinity purification by SDS-PAGE and Western blot. A. Samples analysed in 15\% polyacrilamide gel stained with Commassie blue. Lane 1, Molecular weight markers; Lane 2, E. coli BL21(DE3)pLysS-pRSET without insert; Lane 3, BL21(DE3)pLysS-pRSET-calL-2; Lane 4, affinity purified rcalL-2-F43L. B. Samples evaluated by Western blot developed with an anti-His tag monoclonal antibody conjugated with alkaline phosphatase. Lane 1, E. coli BL21(DE3)pLysS-pRSET without insert; Lane 2, BL21(DE3)pLysS-pRSET-calL-2; Lane 3, affinity purified rcalL-2-F43L; and Lane 4, affinity purified His-tagged enhanced green fluorescent protein (EGFP, positive control). Arrows and arrow head indicate rcalL-2F43L and EGFP bands, respectively. 
incubated with supplemented RPMI 1640 alone (Figure 2A). However, the proliferation peak was reached when rcalL-2F43L was used at $140 \mathrm{ng} / \mathrm{mL}(\mathrm{M}=20,380)$ (Figure 2A).

COS-7 cells calL-2 SN also induced proliferation of CTLL-2 cells when used at concentrations ranging from $0.39 \%(M=2,272)$ to $12.5 \%(M=21,110)$, as compared with cells incubated with COS-7 SN-negative control (highest value of $\mathrm{M}=10$ ) (Figure $2 \mathrm{~B}$ ). Interestingly, the proliferation peak was reached with COS-7 calL-2 SN at $6.25 \%(M=25,068)$ (Figure 2B). These data indicated that both the recombinant protein produced in $E$. coli and refolded and the one produced in COS-7 cells is functionally active.

\section{Proliferation of resting PBMC stimulated with cloned canine IL-2}

To determine if the rcalL-2 produced in E. coli or the COS-7 calL-2 SN would promote proliferation of resting lymphocytes, PBMC from six healthy dogs were cultured

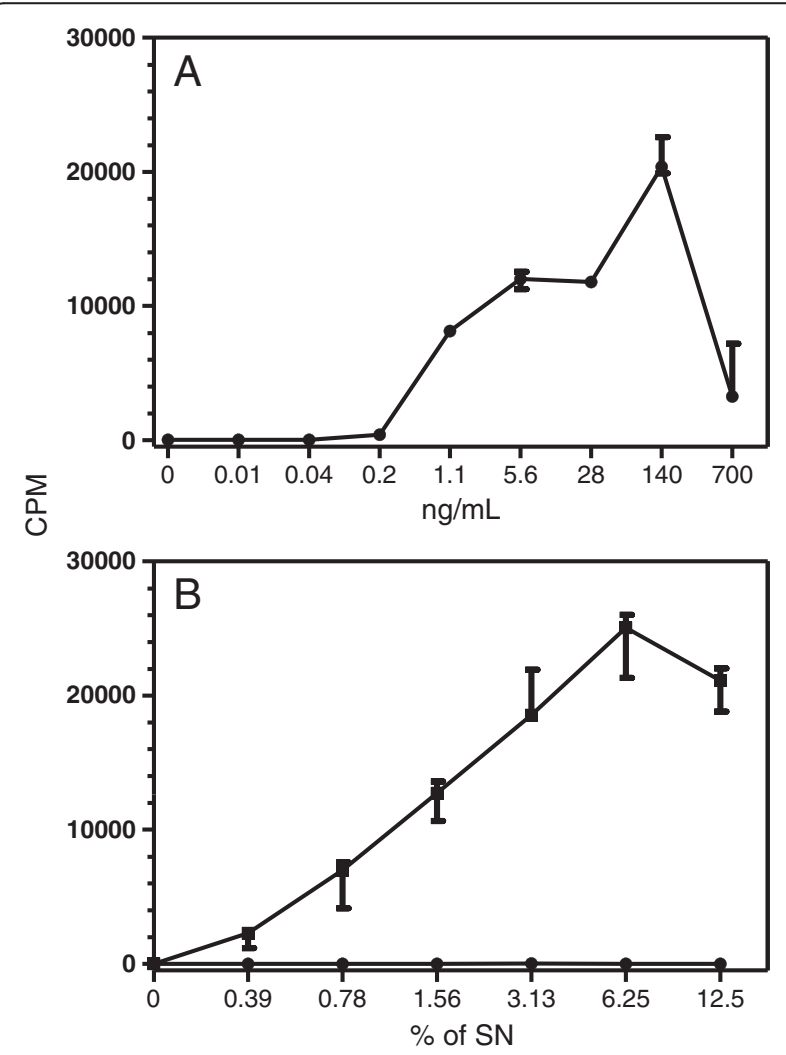

Figure 2 Evaluation of CTLL-2 proliferation following stimulation with recombinant canine IL-2 produced by E. coli or COS-7 cells. CTLL-2 cells were cultured for $48 \mathrm{~h}$ with: (A) different concentrations of affinity purified rcalL-2-F43L produced in E. coli or (B) different concentrations of supernatant of COS-7 cells transfected with pcDNA3.1 without insert (circles) or pcDNA3.1-calL-2 (squares). The cells were pulsed with $3 \mathrm{H}$-thymidine for $24 \mathrm{~h}$. The data represent the median of CPM of triplicates and the bars the 25 and 75 percentiles. for 4 to 14 days with rcalL-2-F43L at $50 \mathrm{ng} / \mathrm{mL}$ or COS7 calL- $2 \mathrm{SN}$ at $0.5,5$ or $50 \%$ and thymidine incorporation was measured. Whereas PBMC cultured in complete RPMI medium alone, used to determine the basal proliferation, presented low incorporation of thymidine, with $C P M$ values ranging from $M=9$ to $M=31$ along the time points assessed, cells cultured with rcaIL-2-F43L displayed significantly higher $\mathrm{CPM}$ values at days $8(\mathrm{M}=3,542), 10$ $(\mathrm{M}=7,854)$ and $12(\mathrm{M}=11,928)$, corresponding to an increase of up to 918 times above the basal levels ( $p<0.05$, Dunn's test; Figure 3A). Moreover, the PBMC incubated with COS-7 caIL-2 SN showed significantly higher thymidine incorporations when tested at $0.5 \%$ for 8 days $(\mathrm{M}=$ 237 vs 14 for the control) and 12 days (262 vs 10$), 5 \%$ for 6 days (388 vs 22), 8 days (2,161 vs 26) and 10 days (2,375 vs 28), and 50\% for 8 days (780 vs 26) and 10 days (735 vs 32 ), reaching up to an 87-fold increase, as compared with the COS-7 SN-negative control (Dunn's test $\mathrm{p}<0.05$, Figure 3B, C and D).

\section{Production of IFN- $\gamma$ by canine PBMC stimulated with recombinant homologous IL-12 and/or IL-2}

To evaluate the ability of the recombinant IL-12 and/or IL-2 to stimulate the production of IFN- $\gamma$ by canine cells, PBMCs from 8 healthy dogs were cultured with different concentrations of COS-7 sccalL-12 SN combined or not with various concentrations of COS-7 caIL-2 $\mathrm{SN}$ for $48 \mathrm{~h}$. The concentration of IFN- $\gamma$ (mean \pm standard deviation) in the supernatant of PMBC cultures carried out with complete RPMI 1640 alone or with the addition of $5 \mu \mathrm{g} / \mathrm{mL}$ Con A was $0.19 \pm 0.26$ and $30.08 \pm 22.56 \mathrm{ng} /$ $\mathrm{mL}$, respectively. PBMC stimulated with only COS-7 sccalL-12 SN at $0.025 \%(1.56 \pm 2.31 \mathrm{ng} / \mathrm{mL}), 0.5 \%(2.36 \pm$ $3.74 \mathrm{ng} / \mathrm{mL}), 10 \%(2.14 \pm 2.50 \mathrm{ng} / \mathrm{mL})$ or COS-7 IL-2 SN at $25 \%(0.52 \pm 0.93 \mathrm{ng} / \mathrm{mL})$ produced a greater amount of IFN- $\gamma$ compared with the cells cultivated with complete RPMI 1640 alone. However, the differences were not significant, probably because only PBMC of 3 or 4 out of 8 dogs and only 1 out of 8 dogs responded to the stimulus of IL-12 and IL-2, respectively (Figure 4). Nevertheless, when PBMC were stimulated with a combination of COS7 sccalL-12 SN at either $0.025 \%(11.34 \pm 11.09 \mathrm{ng} / \mathrm{mL})$, $0.5(13.69 \pm 12.62 \mathrm{ng} / \mathrm{mL})$ or $10 \%(12.73 \pm 13.57)$ and COS-7 calL-2 SN at $25 \%$ or with a combination of COS-7 sccalL-12 SN at either $0.025(9,22 \pm 10,70 \mathrm{ng} / \mathrm{mL})$ or $0.5 \%$ $(16,33 \pm 16,69 \mathrm{ng} / \mathrm{mL})$ and COS-7 caIL-2 SN at $5 \%$, a significant higher production of IFN- $\gamma$ was detected ( $p<0.05$, Dunnett's test; Figure 5$)$. The combined incitation of IL-12 and IL-2 resulted in the response of 6 or 7 out of 8 dogs.

\section{Discussion}

In the present work, we have reported the construction of plasmids encoding the mature and full-length canine 

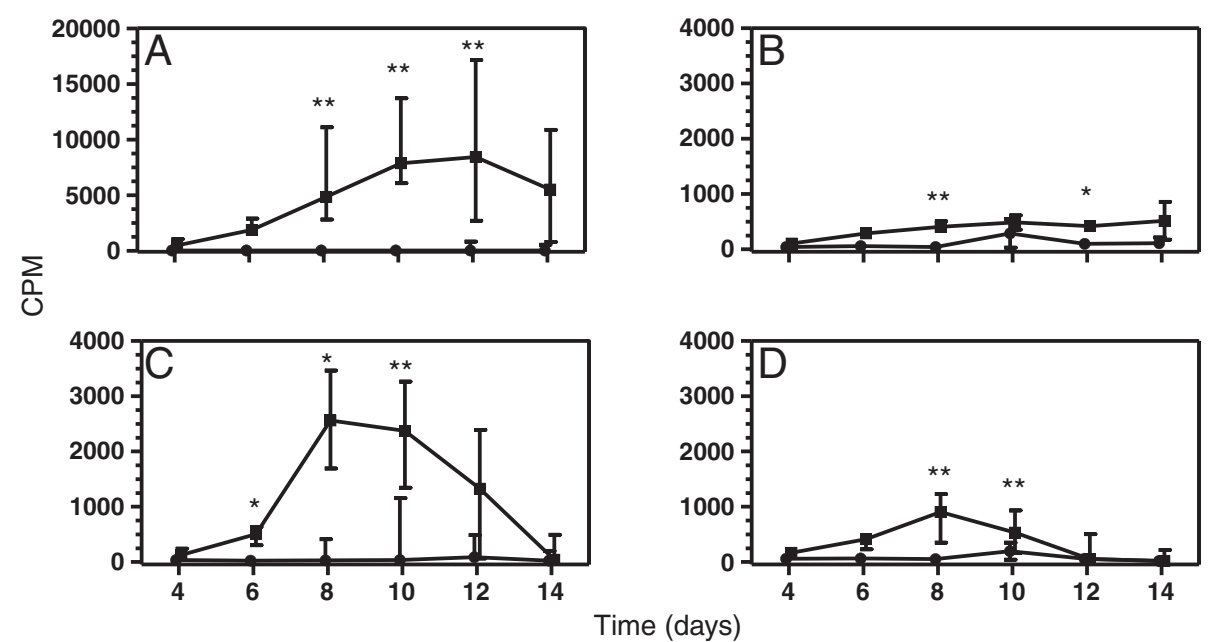

Figure 3 Evaluation of proliferation of canine peripheral blood mononuclear cells (PBMC) stimulated with recombinant canine IL-2 produced by E. coli or COS-7 cells. PBMC of 6 adult mongrel dogs were cultured for 4 to 14 days with: (A) affinity purified rcalL-2-F43L produced in E. coli at $50 \mathrm{ng} / \mathrm{mL}$ (squares) or excipient (circles); (B, C, and D) supernatant of COS-7 cells transfected with either pcDNA3.1 without insert (circles) or pcDNA3.1-call-2 (squares) at 0.5\% (B), 5\% (C) or 50\% (D). The cells were pulsed with 3H-thymidine for $18 \mathrm{~h}$. The data represent the median of the CPM obtained for the six animals and the bars the 25 and 75 percentiles. ${ }^{*} p<0.05,{ }^{* *} p<0.01$; Dunn's post-test $(p<0.001$, Friedman's test).

IL-2 for expression in prokaryotic (pRSET-caIL-2) and eukaryotic cells (pcDNA3.1caIL-2), respectively. Comparing the inserts of the constructions pRSET-caIL-2 and pcDNA3.1-calL-2 with DNA encoding wild-type canine IL-2, previously described by Dunham and collaborators [33], two nucleotide point mutations and complete identity, respectively, was observed. One of the mutations

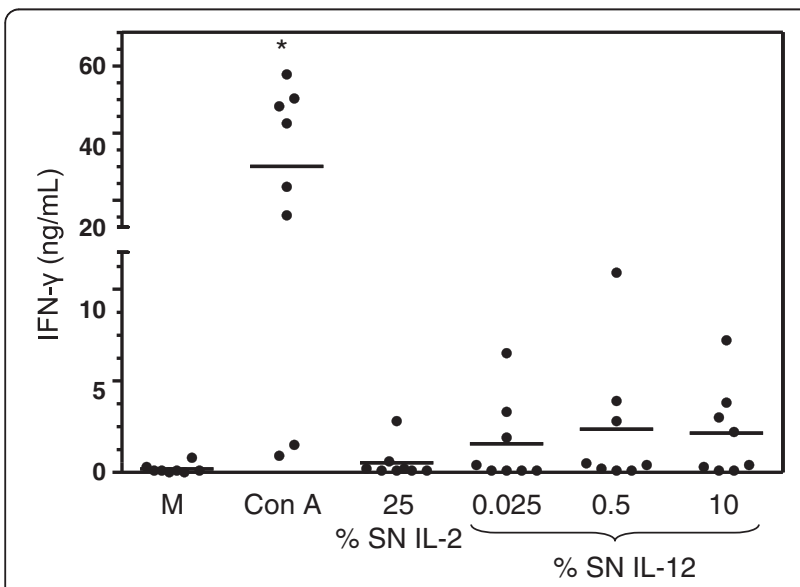

Figure 4 Interferon gamma (IFN- $\gamma$ ) production by peripheral blood mononuclear cells (PBMC) stimulated with recombinant canine IL-2 or IL-12 produced by COS-7 cells. PBMC of 8 adult mongrel dogs were cultured for 48 h with: complete RPMI 1640 medium alone (M), concanavalin $A$ at $5 \mathrm{mg} / \mathrm{mL}$, supernatant of COS-7 cells transfected with pcDNA3.1-calL-2 (SN IL-2) at 25\% or supernatant of COS-7 cells transfected with pcDNA3.1-sccalL-12 (SN IL-12) at $0.025,0.5$ or $10 \%$. IFN- $\gamma$ was assessed in the PBMC supernatants by capture ELISA. Data represent average of duplicates and bars the means obtained for the eight animals. ${ }^{*} p<0.01$, Dunnett's test $(p<0.0001$, repeated measures ANOVA). detected in insert of pRSET-calL-2 was conservative (change to amino acid with similar characteristics) and the other was silent. These mutations have probably occurred due to error in the incorporation of nucleotides carried out by the Taq polymerase used in the PCR reaction [35]. However, it is unlikely that the conservative change of a single amino acid residue would influence too much on the physicochemical characteristics of the protein and interfere with its biological properties. In fact, to determine the impact of such mutation, a tridimensional structure model of canine rcalL-2-F43L was made using tools of the Swiss Model (http://swissmodel.expasy.org/) and PyMol software (http://www.pymol.org/) and crystallized human IL-2 (pdb IM47) as a reference protein. The tridimensional structure model of rcaIL-2-F43L and human IL-2 showed no significant differences one from another (data not shown).

The pRSET-caIL-2 construction induced the production of rcaIL-2-F43L in the form of inclusion bodies in E. coli [36]. In order to refold the rIL-2-F43L, the inclusion bodies were solubilized with a buffer containing urea, the protein was affinity purified and subjected to dialysis to slowly remove the chaotropic agent and allow the formation of the disulfide bridge between the cysteines at positions 59 and 107 of the mature protein (which corresponds to the bridge between amino acid 58 and 105 of the human homologous protein), using a previously described method [31]. This disulfide bridge favors the stabilization of the molecule $[33,37,38]$. Unfortunately, after being subjected to refolding, the rcaIL-2-F43L showed some degree of instability and a progressive reduction in the concentration of soluble protein in the recombinant 


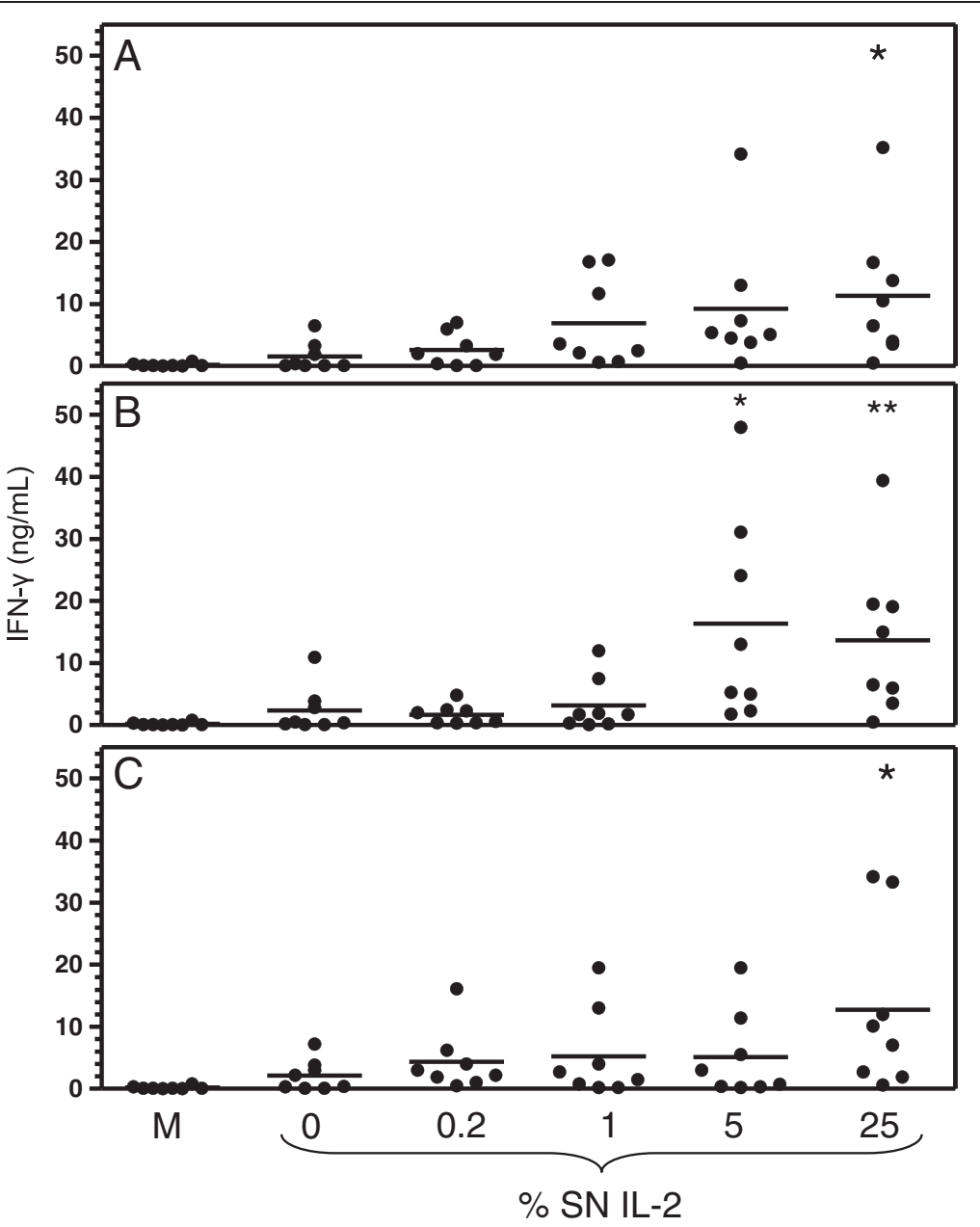

Figure 5 Interferon gamma (IFN- - ) production by peripheral blood mononuclear cells (PBMC) stimulated with recombinant canine IL-2 and/or IL-12 produced by COS-7 cells. PBMC of 8 adult mongrel dogs were cultured for $48 \mathrm{~h}$ with: a) complete RPMI 1640 medium alone (M), b) supernatant of COS-7 cells transfected with pcDNA3.1-calL-2 (SN IL-2) at 0, 0.2, 1, 5 or 25\% in combination with supernatant of COS-7 cells transfected with pcDNA3.1-sccalL-12 at 0.025 (A), 0.5 (B) or 10\% (C). IFN- $\gamma$ was assessed in the PBMC supernatants by capture ELISA. Data represent average of duplicates and bars the means obtained for the eight animals. ${ }^{*} p<0.05,{ }^{* *} p<0.01$; Dunnett's test $(p<0.0001$, repeated measures ANOVA).

interleukin preparation was noted, even when it was stored at $-20^{\circ} \mathrm{C}$ (data not shown). This may have happened by adherence of part of the protein to the tube used for storage or aggregation. Interestingly, the canine IL-2 recently produced in our laboratory using the baculovirus/ insect system seemed to be stable during storage at $-20^{\circ} \mathrm{C}$ (unpublished results).

Cerruti-Sola and collaborators [32] have previously reported that the native canine IL-2 was able to induce proliferation of CTLL-2 cells [39], a murine IL-2dependent $\mathrm{CD}^{+} \mathrm{T}$ cell line. In the current work, rcaIL-2F43L or COS-7 caIL-2 SN stimulated the proliferation of CTLL- 2 cells in a dose-dependent manner, indicating that the cytokine produced in E. coli and COS-7 cells is biologically active. The maximal proliferation induced by rcalL-2-F43L or COS-7 caIL-2 SN was lower than that promoted by T-STIM. This probably happened due to the fact that, in addition to IL-2, the latter contains other(s) factor(s), including IL-4, also capable of stimulating CTLL-2 cell proliferation [40]. Interestingly, the highest concentration of either rcalL-2F43L (700 ng/mL), COS-7 caIL-2 SN [50 or $25 \%$ (data not shown) and $12.5 \%$ ] or T-STIM (50\%, data not shown) stimulated the proliferation of CTLL2 cells at a lower level than the maximum. This is probably due to an inhibitory activity of high concentrations of IL-2, or other factors present in the SN, as previously described for human lymphocytes [41].

Several authors have reported that resting NK cells, $\mathrm{CD}^{+} \mathrm{T}$ lymphocytes, and $\mathrm{CD}^{+} \mathrm{T}$ lymphocytes from peripheral blood could proliferate when stimulated with rhuIL-2 or recombinant murine IL-2 [12,42-45]. In fact, 
resting lymphocytes that constitutively express moderate or high affinity IL-2 receptor, including NK cells, NKT cells, regulatory $\mathrm{T}$ cells and $\mathrm{CD} 8^{+}$memory $\mathrm{T}$ cells (reviewed in [46]), have the potential to proliferate when stimulated in vitro without the need of an additional spur.

To determine whether recombinant canine IL-2 could also induce proliferation of resting lymphocytes, PBMC from six healthy dogs were cultured for 4 to 14 days with rcalL-2-F43L at $50 \mathrm{ng} / \mathrm{mL}$ or with COS-7 calL-2 SN $(0.5,5$ or $50 \%)$. Indeed, after 6 to 12 days of stimulation, the peripheral blood lymphocytes showed a proliferative response. Previously, Helfand and collaborators, in 1992, reported similar results using rhuIL-2 at $25 \mathrm{U} / \mathrm{mL}$ on PBMC of five healthy dogs, showing an increase of proliferation starting by day 5 and peaking by day 8 to 10 of culture [12].

IL-12 stimulates the production of IFN- $\gamma$ by NK cells and T cells and thereby favors the development of Th1 immune responses (reviewed in [11]). In addition, rhuIL-2 synergizes with IL-12 in the production of IFN- $\gamma$ in humans $[27,28]$.

To determine the capacity of canine IL-12 and/or canine IL-2 to promote production of IFN- $\gamma$, PBMC from eight healthy dogs were cultured with COS-7 sccalL-12 SN $(0.025,0.5$ or $10 \%)$ or COS-7 caIL- 2 SN (25\%) or the combination of COS-7 sccalL-12 SN (0.025, 0.5 or $10 \%)$ and calL- 2 SN $(0.2,1,5$ or $25 \%)$. Interestingly, only around half and the minority of the dogs produced IFN$\gamma$ after the stimulation with COS-7 sccalL-12 SN alone or COS-7 calL-2 SN alone, respectively, in comparison with the COS-7 SN-negative control. However, when COS-7 sccalL-12 SN $(0.025,0.5$ or $10 \%)$ was used in combination with COS-7 calL-2 SN (5 or 25\%), PMBC of the majority of dogs synthesized IFN- $\gamma$. Such a response to IL-12 and/or IL-2 seems to be very heterogeneous in the population of dogs studied. The data shown herein are in agreement with reports suggesting that IL-2 alone induces the production of IFN- $\gamma$ in human cells only when used at high concentrations (above $100 \mathrm{U} / \mathrm{mL}$, corresponding to $10 \mathrm{ng} / \mathrm{ml}$ ) [43,45] and IL-12 by itself promotes the synthesis of low amounts of IFN- $\gamma$ in lymphocytes $[23,27,29,47]$.

The results described in this study encourage the evaluation of the effects of the administration of rsccalL-12 and/or rcalL-2 in dogs, aiming at modulating their immune system, for the development of prophylactic and therapeutic protocols for various diseases. In such studies, low doses of IL-2 and IL-12 could be used in combination, resulting in little toxicity. Those doses alone would be ineffective but, in combination, would promote desirable biological effects [48]. For this, rcalL-2 produced in the baculovirus/insect cell system (BEV) (unpublished results) and rsccalL-12 also produced in BEV (manuscript in preparation) could be used. In addition, it would be interesting to determine which are the peripheral blood lymphocyte subpopulations that synthesize interferon gamma when stimulated in vitro by the recombinant canine cytokines. This could be achieved by culturing the cells, either in bulk or separated in subpopulations, staining them with anti-cytokine and anti-lymphocyte subpopulation markers fluorescent antibodies and analyzing them by flow cytometry.

An undesirable effect that may result from the use of IL-12 alone or in combination with IL-2, hampering the development of cellular immune responses, would be the expression of IL-10 [49]. Indeed, several authors have reported that treatment with IL-12 and/or IL-2 promotes IL-10 synthesis in T cell clones (Th0, Th1, and Th2), and in peripheral blood cells co-stimulated with anti-CD3 or Con A, in mice [50-52]. Therefore, perhaps, the use of IL-12 and/or IL-2 should be combined with some sort of strategy for blocking IL-10 stimulation, such as the utilization of antagonist peptides, aptamers [53-55], neutralizing antibodies for IL-10 or for the IL-10 receptor (IL-10R1) [56,57], and soluble IL-10 receptor (sIL-10R1) [58,59].

\section{Conclusions}

The results presented herein suggest that the combination of recombinant canine IL-12 and IL- 2 can be useful to promote cellular immune responses in dogs.

\section{Competing interests}

The authors declare that they have no competing interests.

\section{Authors' contributions}

AMP was involved in planning and carrying out some of the experiments (DNA cloning, protein expression and the ex vivo and in vitro assays), data analysis and in manuscript writing. CGMP was involved in carrying out some of the experiments (ex vivo assays and in vitro assays) and manuscript writing. LRS was involved in planning and carrying out some of the experiments (DNA cloning, protein expression and the ex vivo and in vitro assays) and data analysis. NCT was involved in carrying out some of the experiments (in vitro assays) and manuscript writing. Y-FC was involved in planning and some of the experiments (DNA cloning). LCPC was involved in planning the study and manuscript writing. GGSO was involved in planning the study and manuscript writing. All authors read and approved the final manuscript.

\section{Acknowledgements}

The authors would like to thank Mr. Márcio da Silva Rodrigues, the DNA Sequencing Platform, CPqGM, FIOCRUZ, and Mr. Jedson Ferreira Cardoso, Instituto Evandro Chagas, FIOCRUZ, the for technical assistance in IL-2 cloning, DNA sequencing, and canine IL-2 three dimensional structure in silico modeling, respectively.

\section{Funding}

Conselho Nacional de Desenvolvimento Científico e Tecnológico (CNPq). Rede Nordeste de Biotecnologia (RENORBIO), Ministério de Ciência e Tecnologia.

Programa INOVABIO, Ministério da Saúde.

Instituto Nacional de Ciência e Tecnologia de Doenças Tropicais (INCT-DT).

\section{Author details}

'Laboratório de Patologia e Bio-Intervenção, Centro de Pesquisas Gonçalo Moniz, Fundação Oswaldo Cruz, Rua Waldemar Falcão, No. 121, Candeal, Salvador, Bahia, Brazil. ²Department of Population Medicine and 
Diagnostic Sciences, College of Veterinary Medicine, Cornell University, Ithaca, NY, USA. ${ }^{3}$ Instituto Nacional de Ciência e Tecnologia de Doenças Tropicais (INCT-DT), Salvador, Bahia, Brazil.

Received: 10 March 2014 Accepted: 30 June 2014

Published: 18 July 2014

\section{References}

1. Dinarello CA: Historical insights into cytokines. Eur J Immunol 2007, 37(Suppl 1):S34-S45.

2. Boyman O, Purton JF, Surh CD, Sprent J: Cytokines and T-cell homeostasis. Curr Opin Immunol 2007, 19(3):320-326.

3. Bezbradica JS, Medzhitov R: Integration of cytokine and heterologous receptor signaling pathways. Nat Immunol 2009, 10(4):333-339.

4. Paul WE: Fundamental Immunoloy. Philadelphia: Lippincott Williams \& Wilkins; 2008.

5. Watson J, Gillis S, Marbrook J, Mochizuki D, Smith KA: Biochemical and biological characterization of lymphocyte regulatory molecules. I. purification of a class of murine lymphokines. J Exp Med 1979, 150(4):849-861.

6. Taniguchi T, Matsui H, Fujita T, Takaoka C, Kashima N, Yoshimoto R, Hamuro J: Structure and expression of a cloned cDNA for human interleukin-2. Nature 1983, 302(5906):305-310.

7. Sojka DK, Bruniquel D, Schwartz RH, Singh NJ: IL-2 secretion by CD4+ T cells in vivo is rapid, transient, and influenced by TCR-specific competition. $\mathrm{J}$ Immunol 2004, 172(10):6136-6143.

8. D'Souza WN, Lefrancois L: Frontline: an in-depth evaluation of the production of IL-2 by antigen-specific CD8 T cells in vivo. Eur J Immunol 2004, 34(11):2977-2985.

9. Boyman O, Sprent J: The role of interleukin-2 during homeostasis and activation of the immune system. Nat Rev Immunol 2012, 12(3):180-190.

10. Trinchieri G, Gerosa F: Immunoregulation by interleukin-12. J Leukoc Biol 1996, 59(4):505-511.

11. Trinchieri G: Interleukin-12 and the regulation of innate resistance and adaptive immunity. Nat Rev Immunol 2003, 3(2):133-146.

12. Helfand SC, Modiano JF, Nowell PC: Immunophysiological studies of interleukin-2 and canine lymphocytes. Vet Immunol Immunopathol 1992, 33(1-2):1-16.

13. Helfand SC, Soergel SA, Modiano JF, Hank JA, Sondel PM: Induction of lymphokine-activated killer (LAK) activity in canine lymphocytes with low dose human recombinant interleukin-2 in vitro. Cancer Biother 1994 9(3):237-244.

14. G. R. Cain TK, N Taylor I, Champlin R: Effects of administration of Recombinant Human Interleukin-2 in dogs. Comp Haematol Int 1992, 2:201-207.

15. Ohnishi H, Okuno K, Yasutomi M: Successful in vivo generation of canine lymphokine-activated killer cells by continuous recombinant interleukin-2 infusion through the splenic artery. Cancer Biother 1993, 8(3):213-222.

16. Helfand SC, Soergel SA, MacWilliams PS, Hank JA, Sondel PM: Clinical and immunological effects of human recombinant interleukin-2 given by repetitive weekly infusion to normal dogs. Cancer Immunol Immunother 1994, 39(2):84-92.

17. Phillips BS, Padilla ML, Dickerson EB, Lindstrom MJ, Helfand SC: Immunostimulatory effects of human recombinant interleukin-12 on peripheral blood mononuclear cells from normal dogs. Vet Immunol Immunopathol 1999, 70(3-4):189-201.

18. Cemazar MSG, Pavlin D, Tozon N: Intramuscular IL-12 Electrogene Therapy for Treatment of Spontaneous Canine Tumors. In Targets in gene therapy. Edited by You Y. Rijeka, Croatia: Rijeka: InTech; 2011:299-320.

19. Okano F, Satoh M, Yamada K: Cloning and expression of the CDNA for canine interleukin-12. J Interferon Cytokine Res 1997, 17(11):713-718.

20. dos Santos LR, Barrouin-Melo SM, Chang YF, Olsen J, McDonough SP, Quimby F, dos Santos WL, Pontes-de-Carvalho LC, Oliveira GG: Recombinant single-chain canine interleukin 12 induces interferon gamma mRNA expression in peripheral blood mononuclear cells of dogs with visceral leishmaniasis. Vet Immunol Immunopathol 2004, 98(1-2):43-48.

21. Poot J, Spreeuwenberg K, Sanderson SJ, Schijns VE, Mottram JC, Coombs GH, Vermeulen AN: Vaccination with a preparation based on recombinant cysteine peptidases and canine IL-12 does not protect dogs from infection with Leishmania infantum. Vaccine 2006, 24(14):2460-2468.

22. Saldarriaga $O A$, Perez $L E$, Travi BL, Melby PC: Selective enhancement of the type 1 cytokine response by expression of a canine interleukin (IL)-12 fused heterodimeric DNA. Vet Immunol Immunopathol 2006, 110(3-4):377-388.
23. Strauss-Ayali D, Baneth $G$, Shor S, Okano F, Jaffe CL: Interleukin-12 augments a Th1-type immune response manifested as lymphocyte proliferation and interferon gamma production in Leishmania infantum-infected dogs. Int J Parasitol 2005, 35(1):63-73.

24. Sarmiento UM, Riley JH, Knaack PA, Lipman JM, Becker JM, Gately MK, Chizzonite R, Anderson TD: Biologic effects of recombinant human interleukin-12 in squirrel monkeys (Sciureus saimiri). Lab Invest 1994, 71(6):862-873.

25. Nadeau RR, Ostrowski C, Ni-Wu G, Liberato DJ: Pharmacokinetics and pharmacodynamics of recombinant human interleukin-12 in male rhesus monkeys. J Pharmacol Exp Ther 1995, 274(1):78-83.

26. Villinger F, Bostik P, Mayne A, King CL, Genain CP, Weiss WR, Ansari AA: Cloning, sequencing, and homology analysis of nonhuman primate Fas/Fas-ligand and co-stimulatory molecules. Immunogenetics 2001, 53(4):315-328.

27. Kobayashi M, Fitz L, Ryan M, Hewick RM, Clark SC, Chan S, Loudon R, Sherman F, Perussia B, Trinchieri G: Identification and purification of natural killer cell stimulatory factor (NKSF), a cytokine with multiple biologic effects on human lymphocytes. J Exp Med 1989, 170(3):827-845.

28. Wolf SF, Temple PA, Kobayashi M, Young D, Dicig M, Lowe L, Dzialo R, Fitz L, Ferenz C, Hewick RM, Kelleher K, Herrmann SH, Clark SC, Azzoni L, Chan SC, Trinchieri G, Perussia B: Cloning of cDNA for natural killer cell stimulatory factor, a heterodimeric cytokine with multiple biologic effects on $\mathrm{T}$ and natural killer cells. J Immunol 1991, 146(9):3074-3081.

29. Schoenhaut DS, Chua AO, Wolitzky AG, Quinn PM, Dwyer CM, McComas W, Familletti PC, Gately MK, Gubler U: Cloning and expression of murine IL-12. J Immunol 1992, 148(11):3433-3440.

30. Gately MK, Desai BB, Wolitzky AG, Quinn PM, Dwyer CM, Podlaski FJ, Familletti PC, Sinigaglia F, Chizonnite R, Gubler U, Stern AS: Regulation of human lymphocyte proliferation by a heterodimeric cytokine, IL-12 (cytotoxic lymphocyte maturation factor). J Immunol 1991, 147(3):874-882.

31. Guisez Y, Demolder J, Mertens N, Raeymaekers A, Plaetinck G, Robbens J, Vandekerckhove J, Remaut E, Fiers W: High-level expression, purification, and renaturation of recombinant murine interleukin-2 from Escherichia coli. Protein Expr Purif 1993, 4(3):240-246.

32. Cerruti-Sola S, Kristensen F, Vandevelde M, de Weck AL: Interleukin 1- and 2-like activities in the dog. Vet Immunol Immunopathol 1984, 6(3-4):261-271.

33. Dunham SP, Argyle DJ, Onions DE: The isolation and sequence of canine interleukin-2. DNA Seq 1995, 5(3):177-180.

34. Kozak M: Point mutations define a sequence flanking the AUG initiator codon that modulates translation by eukaryotic ribosomes. Cell 1986, 44(2):283-292.

35. Eckert KA, Kunkel TA: High fidelity DNA synthesis by the Thermus aquaticus DNA polymerase. Nucleic Acids Res 1990, 18(13):3739-3744.

36. Schoemaker JM, Brasnett AH, Marston FA: Examination of calf prochymosin accumulation in Escherichia coli: disulphide linkages are a structural component of prochymosin-containing inclusion bodies. Embo J 1985, 4(3):775-780.

37. Wang A, Lu SD, Mark DF: Site-specific mutagenesis of the human interleukin-2 gene: structure-function analysis of the cysteine residues. Science 1984, 224(4656):1431-1433.

38. Ju G, Collins L, Kaffka KL, Tsien WH, Chizzonite R, Crowl R, Bhatt R, Kilian PL: Structure-function analysis of human interleukin-2. identification of amino acid residues required for biological activity. J Biol Chem 1987, 262(12):5723-5731.

39. Gillis S, Ferm MM, Ou W, Smith KA: T cell growth factor: parameters of production and a quantitative microassay for activity. J Immunol 1978, 120(6):2027-2032.

40. Hu-Li J, Ohara J, Watson C, Tsang W, Paul WE: Derivation of a T cell line that is highly responsive to IL-4 and IL-2 (CT.4R) and of an IL-2 hyporesponsive mutant of that line (CT.4S). J Immunol 1989, 142(3):800-807.

41. Lakhanpal S, Gonchoroff NJ, Handwerger BS: Interleukin 2 induces proliferation of normal "resting" human T cells in the absence of other known external stimulation. Cell Immunol 1987, 106(1):62-75.

42. Helfand SC, Modiano JF, Moore PF, Soergel SA, MacWilliams PS, Dubielzig RD, Hank JA, Gelfand EW, Sondel PM: Functional interleukin-2 receptors are expressed on natural killer-like leukemic cells from a dog with cutaneous lymphoma. Blood 1995, 86(2):636-645.

43. Treiber-Held S, Stewart DM, Barraclough HA, Kurman CC, Nelson DL: Release of sIL-2R alpha from and activation of native human peripheral blood mononuclear cells by recombinant IL-15. Clin Immunol Immunopathol 1996, 80(1):67-75. 
44. Boyman O, Kovar M, Rubinstein MP, Surh CD, Sprent J: Selective stimulation of T cell subsets with antibody-cytokine immune complexes. Science 2006, 311(5769):1924-1927.

45. Krieg C, Letourneau S, Pantaleo G, Boyman O: Improved IL-2 immunotherapy by selective stimulation of IL-2 receptors on lymphocytes and endothelial cells. Proc Natl Acad Sci U S A 2010, 107(26):11906-11911.

46. Malek TR: The biology of interleukin-2. Annu Rev Immunol 2008, 26:453-479.

47. Chan SH, Perussia B, Gupta JW, Kobayashi M, Pospisil M, Young HA, Wolf SF, Young D, Clark SC, Trinchieri G: Induction of interferon gamma production by natural killer cell stimulatory factor: characterization of the responder cells and synergy with other inducers. J Exp Med 1991, 173(4):869-879.

48. Kaufman $\mathrm{HL}$, Flanagan $\mathrm{K}$, Lee $\mathrm{CS}$, Perretta DJ, Horig H: Insertion of interleukin-2 (IL-2) and interleukin-12 (IL-12) genes into vaccinia virus results in effective anti-tumor responses without toxicity. Vaccine 2002, 20(13-14):1862-1869.

49. O'Garra A, Barrat FJ, Castro AG, Vicari A, Hawrylowicz C: Strategies for use of IL-10 or its antagonists in human disease. Immunol Rev 2008, 223:114-131.

50. Jeannin $P$, Delneste $Y$, Seveso M, Life P, Bonnefoy JY: IL-12 synergizes with IL-2 and other stimuli in inducing IL-10 production by human T cells. J Immunol 1996, 156(9):3159-3165.

51. Lauw FN, Dekkers PE, te Velde AA, Speelman P, Levi M, Kurimoto M, Hack CE, van Deventer SJ, van der Poll T: Interleukin-12 induces sustained activation of multiple host inflammatory mediator systems in chimpanzees. J Infect Dis 1999, 179(3):646-652.

52. Takeuchi $E$, Yanagawa $H$, Suzuki $Y$, Shinkawa $K$, Ohmoto $Y$, Bando $H$, Sone S: IL-12-induced production of IL-10 and interferon-gamma by mononuclear cells in lung cancer-associated malignant pleural effusions. Lung Cancer 2002, 35(2):171-177.

53. Cardone AOPMA, Andrew Stewart C, Tarasova NI, Giorgio T, Young HA Peptide-based inhibitor of interleukin-10 or interferon-gamma signaling In. United States of America: Office USPaT, vol. PCT/US2011/036010; 2011.

54. Berezhnoy A, Stewart CA, McNamara JO 2nd, Thiel W, Giangrande P, Trinchieri G, Gilboa E: Isolation and optimization of murine IL-10 receptor blocking oligonucleotide aptamers using high-throughput sequencing. Mol Ther 2012, 20(6):1242-1250.

55. Naiyer MM, Saha S, Hemke V, Roy S, Singh S, Musti KV, Saha B. Identification and characterization of a human $\mathrm{IL}-10$ receptor antagonist. Hum Immunol 2013, 74(1):28-31.

56. Hagenbaugh A, Sharma S, Dubinett SM, Wei SH, Aranda R, Cheroutre H, Fowell DJ, Binder S, Tsao B, Locksley RM, Moore KW, Kronenberg M: Altered immune responses in interleukin 10 transgenic mice. J Exp Med 1997 185(12):2101-2110.

57. Murray HW, Lu CM, Mauze S, Freeman S, Moreira AL, Kaplan G, Coffman RL: Interleukin-10 (IL-10) in experimental visceral leishmaniasis and IL-10 receptor blockade as immunotherapy. Infect Immun 2002, 70(11):6284-6293.

58. Rigopoulou El, Abbott WG, Haigh P, Naoumov NV: Blocking of interleukin-10 receptor-a novel approach to stimulate T-helper cell type 1 responses to hepatitis C virus. Clin Immunol 2005, 117(1):57-64.

59. Marchi LH, Paschoalin T, Travassos LR, Rodrigues EG: Gene therapy with interleukin-10 receptor and interleukin-12 induces a protective interferon-gamma-dependent response against B16F10-Nex2 melanoma. Cancer Gene Ther 2011, 18(2):110-122.

\section{Submit your next manuscript to BioMed Central and take full advantage of:}

- Convenient online submission

- Thorough peer review

- No space constraints or color figure charges

- Immediate publication on acceptance

- Inclusion in PubMed, CAS, Scopus and Google Scholar

- Research which is freely available for redistribution

Submit your manuscript at www.biomedcentral.com/submit
C BioMed Central 